\title{
Familial late onset oculopharyngeal muscular dystrophy
}

\author{
D. A. ISENBERG \\ M.R.C.P.
}

Pauline Kahn

M.B., Ch.,B.

Department of Neurology, Whittington Hospital, Dartmouth Park Hill, London, N.9

\begin{abstract}
Summary
An English family is described several members of which have suffered from oculopharyngeal muscular dystrophy. No symptoms were noticed in any affected members of the family until aged at least 50 years. An autosomal dominant pattern of inheritance is clearly shown.
\end{abstract}

\section{Case reports}

The family tree of the initial patient II 2 is shown in Fig. 1. In February 1979 when aged 75 years she was

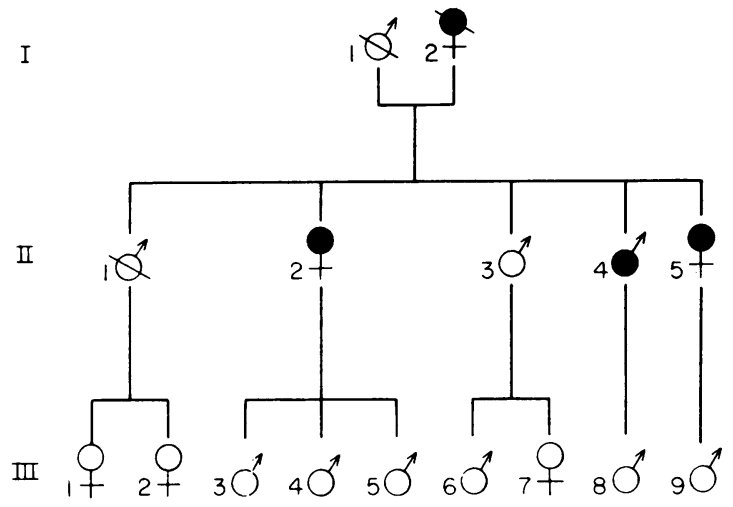

Late onset oculopharyngeal muscular dystrophy

Died

Fig. 1. Family tree.

treated as an in-patient for lobar pneumonia. During her recovery the bilateral ptosis which had been noted on admission was further enquired into.

She had first noticed mild bilateral ptosis when aged about 60 years. This had slowly progressed. When aged about 70 years she had noticed some weakness in her legs, so that she had difficulty in rising from a chair and in walking. This, too, had slowly worsened. Aged about 72 years she had first noticed difficulty in swallowing solids; as a result she had lost $6.4 \mathrm{~kg}$ in weight over a 3 -year period.
On examination she was a pleasant, intelligent woman with obvious marked bilateral ptosis (Fig. 2). She had slight wasting and weakness of her temporalis, masseter and facial muscles bilaterally. There were no other cranial nerve abnormalities, in particular she had full extra-ocular eye movements.

In her upper limbs there was diffuse muscle wasting, especially in the proximal muscle groups. Tone was normal but her power was impaired in accordance with the degree of wasting. There were no sensory abnormalities and the tendon reflexes were all present though diminished.

In the lower limbs the pattern was similar, with wasting and weakness more marked proximally. Tone was normal, but vibration sensation was absent below the anterior superior iliac spines bilaterally. Knee and ankle jerks were absent bilaterally and plantar responses were flexor.

The serum creatine phosphokinase (CPK) level was 45 i.u./l. (upper limit of normal is 50 i.u./l.) but electromyography showed widespread myopathic changes.

Histological demonstration of severe changes in this form of dystrophy is difficult because the extraocular muscles are inaccessible to biopsy. This patient had mild quadriceps muscle weakness and needle biopsy (Edwards and Maunder, 1977) showed changes of primary muscle disease. There was scattered fibre atrophy including some small angular fibres (Fig. 3). A few internal nuclei were noted and endomysial connective tissue was mildly increased. Cytochemical studies confirmed dispersed atrophic fibres of both type 1 and type 2 variety (Fig. 4). In the modified Gomori-trichrome preparations, occasional dark fibres some with dark peripheral staining were seen, a feature described by Morgan-Hughes and Mair in their description of 4 patients with oculo-skeletal myopathy (Morgan-Hughes and Mair, 1973). In their cases most fibres were of normal size, a few were atrophic and sometimes angular in outline. The major pathological changes in their study were in the muscle mitochondria which showed proliferation and crystalline inclusions in both muscle 
fibre types. Unfortunately, electronmicroscopy was not undertaken in the study of this patient, but the appearances of the biopsy on light miscroscopy supported the diagnosis of muscular dystrophy.

A barium swallow was within normal limits.

\section{Patient I2}

The mother of patient II 2 had died aged 69 years. Her daughter recalled that in her early 60 s her mother had developed drooping of both eyelids, difficulty in raising her arms above her head and in walking properly. Towards the end of her life she haळ also intermittent difficulty in swallowing.

\section{Patient II4}

The brother of patient II2 has so far declinech investigation. He has however informed us that hisf ptosis began in his early 60 s and that currently he has no other symptoms.

\section{Patient II5}

The sister of patient II2 developed bilatera施

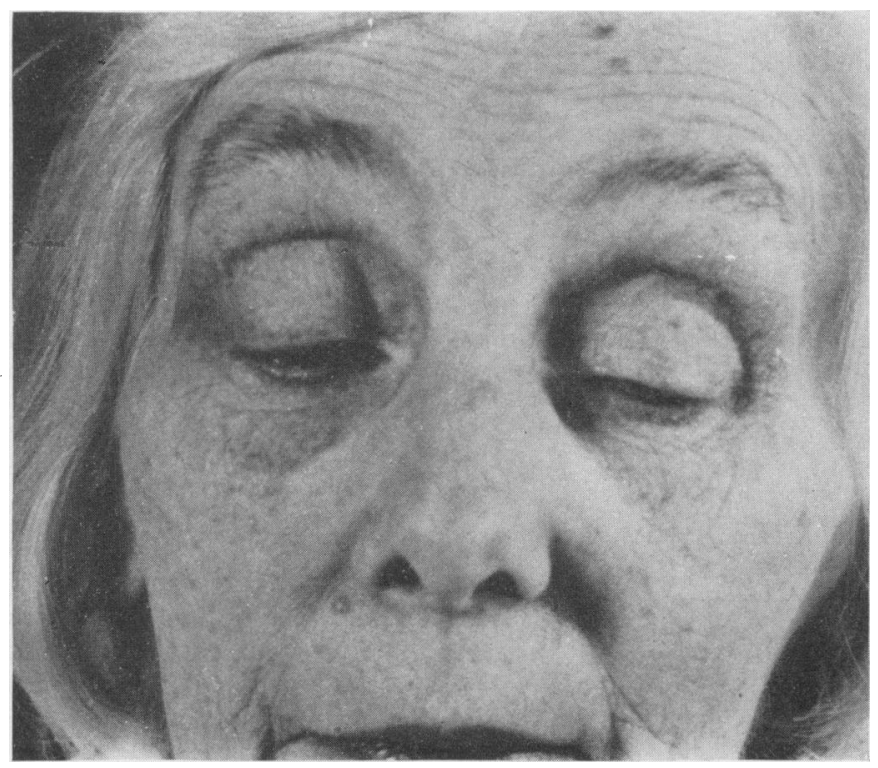

FIG. 2. Case II2 showing ptosis and myopathic facies.

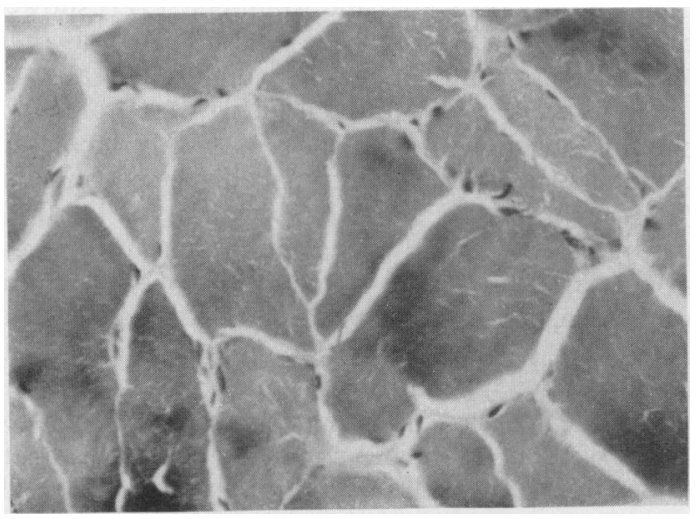

FIG. 3. Scattered single fibre atrophy $(\mathrm{HE}, \times 200)$.

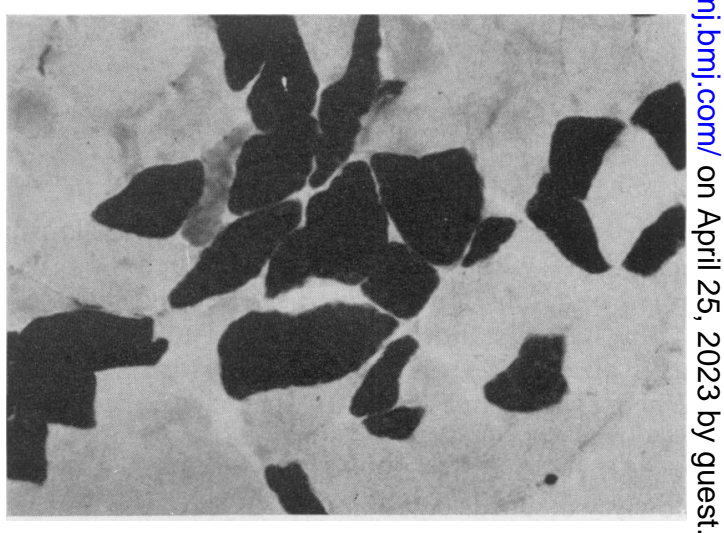

FIG. 4. Fibre atrophy affects Type I and Type II fibres (ATPase pH $9.4 \times 160$ )

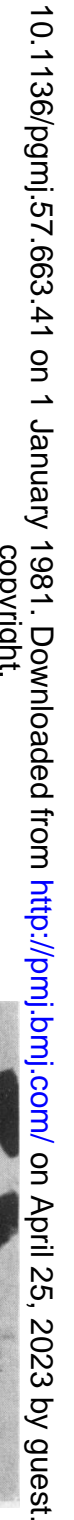


ptosis when aged about 50 years. Although not complaining of any other symptoms, physical examination when aged 70 years revealed some facial weakness and proximal muscle weakness in the upper limbs. A CPK estimation was within normal limits. She declined further investigation.

\section{Discussion}

Thanks principally to the careful studies undertaken by Kiloh and Nevin (1951) the existence of an ocular form of muscular dystrophy is widely accepted. An unusual variant of this condition, in which dysphagia is a prominent feature was first defined as a nosological entity by Victor, Hayes and Adams (1962). They referred to the variant as oculopharyngeal muscular dystrophy. Although Walton (1964) claimed that dysphagia occurs in $50 \%$ of patients with ocular myopathy, Kiloh and Nevin found just 5 patients out of 140 with this symptom. Bray, Kaarsoo and Ross (1965) also found that only a minority of cases had dysphagia. In their review of 148 cases of ocular myopathy reported between 1948 and 1965 they noted that only $\mathbf{4 3}$ had difficulty with swallowing. They showed that ocular myopathy with dysphagia tends to present at the age of 40 years or over (about 20 years later than simple ocular myopathy), has a higher familial incidence, a greater frequency of facial weakness and ptosis without accompanying ophthalmoplegia. Even though Morgan-Hughes and Mair (1973) demonstrated the overlap that may occur between the 2 types, the family now described would certainly fit the category of oculopharyngeal dystrophy very well.

Interestingly, the vast majority of familial cases of oculopharyngeal dystrophy have been of FrenchCanadian ancestry. Barbeau (1966) traced 160 affec- ted people, descendants of a couple who settled near Quebec in the 1600s. Reports of families with other ethnic origins are scanty. Victor et al. (1962) described a Jewish family originating in Eastern Europe. Dubowitz and Brooke (1973) described several families in Colorado of Spanish-American descent. The family now described has no known French ancestry.

Elevated CPK levels have been reported in the children and grandchildren of these patients (Barbeau, 1966), however the CPK levels of the 3 children of the patient II2 (III3, 4, 5) were estimated, and found to be normal.

\section{Acknowledgment}

We would like to thank Dr J. Milnes for permission to describe case II 2 .

\section{References}

Barbeau, A. (1966) The syndrome of hereditary late onset ptosis and dysphagia in French-Canada. In: Symposium über progressive Muskeldystrophie (Ed by Huhn, E.), pp. 102-109. Springer-Verlag, Berlin.

Bray, G.M., KaArsoo, M. \& Ross, R.T. (1965) Ocular myopathy with dysphagia. Neurology. Minneapolis, 15, 678.

Dubowitz, V. \& Brooke, M.H. (1973) Muscle Biopsy: A Modern Approach. pp. 231-240. Saunders, London.

Edwards, R.H.T. \& Maunder, C. (1977) Muscle biopsy. Hospital Update, 3, 569.

KILOH, L.G. \& Nevin, S. (1951) Progressive dystrophy of the external ocular muscles (ocular myopathy). Brain, 74, 115.

Morgan-Hughes, J.A. \& MaIr, W.G.P. (1973) Atypical muscle mitochondria in oculoskeletal myopathy. Brain, 96, 215.

Victor, M., Hayes, R. \& Adams, R.D. (1962) Oculopharyngeal muscular dystrophy. New England Journal of Medicine, 267, 1267.

Walton, J.N. (1964) Muscular dystrophy: Some recent advances in knowledge. British Medical Journal, 1, 1271. 